\title{
The scope of the crustacean immune system for disease control
}

\section{Chris Hauton}

Ocean and Earth Science,

National Oceanography Centre Southampton,

University of Southampton Waterfront Campus,

European Way,

Southampton,

SO14 3ZH,

ch10@noc.soton.ac.uk

Ph: +44 (0)2380 595784

Fx: + $44(0) 2380593059$ 


\begin{abstract}
The culture or wild capture of marine and freshwater shellfish, including crustaceans, is without doubt a key source of protein for a burgeoning world population. Historically the expansion of aquaculture has, however, been accompanied by the increased incidence of economically significant diseases, most notably of viral and bacterial origin. Since the late 1970s great progress has been made in our understanding of the generalized protostome innate immune system. Distinct pathways, pathogen receptor proteins and effector molecules have since been identified that are not ancestral or homologous to those of the deuterostomes, including vertebrates. Within the past decade progress has accelerated with the rapid characterisation of new classes of recognition proteins, immune effectors and regulatory pathways. This paper provides a broad overview of our current understanding of invertebrate immunology, taking the crustacean decapod immune system as its focus. Recent developments in the field are described briefly and their implications and potential considered. These advances offer fundamental new insights in our efforts to understand disease in cultured populations and also to develop knowledge of environmental effects on host/pathogen interactions within a fishery context. Of course, challenges do remain, including the lack of an immortal cell line and the limited publically-available genomic resources. These are considered in this review as priorities for future research effort. With the continued application of more insightful technologies, coupled with associated investment, it is expected that the speed at which some of these issues are resolved will accelerate.
\end{abstract}

\title{
Keywords
}

Crustacean, Immunity, Disease, Aquaculture, Virus, Bacteria 


\section{Introduction}

For future generations, and in response to the increasing global population, the reliance on crustacean shellfish as a source of animal protein is set to increase. Inevitably this will lead to an increase in demand from wild fishery stocks and expansion of aquaculture (Subasinghe et al., 2009, Stentiford et al., 2012). However, the expansion of fishery effort in wild species and the increase in aquaculture across new species and new countries are not without significant issue, including the potential for habitat destruction, socioeconomic challenges, an increased prevalence or geographic spread of existing diseases and the potential for new diseases to arise.

Pathogens of commercial significance to the global crustacean shellfish industry (fisheries and aquaculture) have been reviewed in detail by other contributions to this volume. As described, significant economic global impacts are caused by viruses (e.g. White Spot Syndrome Virus (WSSV) and Infectious Hypodermal and Haematopoietic Necrosis Virus (IHHNV)), Gram-negative bacteria (e.g. Vibrio harveyi, Vibrio penaecidia, and opportunistic vibrios) and protozoa (e.g. Hematodinium spp.). Regionally, other pathogens are also commercially significant, including the Gram-positive bacterium, Aerococcus viridans var homari, which detrimentally affects wild-caught lobsters Homarus americanus in Canada and the United States.

The intention of this review is to provide a brief but broad overview of our current understanding of the crustacean innate immune system, with special reference to the Decapoda, and to identify avenues for future focus as part of a suite of solutions to ensure global food security using farmed and wild caught crustacean shellfish.

\section{Current knowledge of the crustacean immune mechanism - an overview}

The immune system of decapods is comprised of both cellular and non-cellular (humoral) components. Whilst this classification is operationally useful it is an artificial distinction. There is considerable integration of the cellular and humoral compartments to produce a single coordinated system. Cellular responses are triggered or enhanced by factors present within the plasma and humoral elements are often produced in, and secreted from, circulating and fixed haemocytes. Components and activities of the decapod innate immune response have been variously reviewed at different times by a number of different groups. Herein only a brief overview is provided, emphasizing the key literature and summarizing the most recent experimental data where appropriate.

\subsection{Diverse families of pattern recognition proteins}


Innate immune responses in Crustacea are triggered by minute quantities of pathogen associated molecular patterns (PAMPs) (Janeway \& Medzhitov, 2002) that include bacterial lipopolysaccharides and peptidoglycans as well as fungal $\beta-1,3$-glucans. Recognition of PAMPs is achieved via a spectrum of pattern recognition proteins (PRPs) and this interaction is instrumental in the activation of several key pathways and the release of a battery of active effector molecules. A suite of PRPs have been characterized from both the Dendrobranchiata and Pleocyemata lineages, including proteins such as lipopolysaccharide- and $\beta$-glucan binding proteins (LGBPs and $\beta$ GBPs) (e.g. Yepiz-Plascencia et al., 1998; Lee et al., 2000; Vargas-Albores \& Yepiz-Plascencia, 2000).

A broad and diverse category of lectin-like proteins have also been described within the Crustacea and are considered to represent another class of PRP. C type lectins all contain one or two carbohydrate recognition domains (CRD) and have a well-defined structure maintained by two or three pairs of disulphide bonds. Within the penaeid shrimp different lectins have been described from hepatopancreas and/or haemocytes and have been shown to be transcriptionally up-regulated in response to infection with some viruses , including WSSV (Luo et al., 2003; Ma et al., 2007; Yang et al., 2007), and Gram-negative bacteria (Luo et al., 2006).

PAMP recognition may involve the formation of receptor complexes. The complexation of $\beta-1,3-$ glucans with a secreted soluble binding protein (e.g. $\beta$ BGP) which subsequently binds to cell surface receptors, such as superoxide dismutase receptors (reviewed by Jiravanichpaisal et al., 2006). In addition, the recognition of bacterially-derived peptidoglycans (PGN) has been described recently for a standard model, the crayfish Pacifastacus leniusculus (Liu et al., 2011). In this species the recognition of PGN does not require a specific peptidoglycan recognition receptor (PGRPs) as widely recorded in the Insecta, but instead appears to be mediated by binding to novel serine proteinase homologues which form complexes to a characterized LGBP.

The formation of receptor complexes is also a feature of the Toll activation pathway which has now been described for a number of decapods. The first Toll receptor was reported in Drosophila melanogaster as a gene whose products control dorsoventral polarity during embryogenesis (Belvin \& Anderson, 1996; Stein et al., 2001). Toll receptors have now been identified in Penaeus monodon (Arts et al., 2007), Penaeus japonicus, (Mekata et al., 2008), P. vannamei (Yang et al., 2007) and P. chinensis (Yang et al., 2008). In mammals a suite of 13 Toll-like receptors (TLRs) are reported with a variety of identified ligands, including PAMPs originating from bacteria, fungi and viruses (West et al., 2006). Triggers for Toll-mediated signalling in decapod crustaceans are less certain, although an involvement in the detection of bacterial PAMPs has been identified in P. chinensis (Yang et al., 2008). Also of significance, a Spätzle homologue in P. chinensis was recently reported (Shi et al., 2009). Spätzle has a 106 residue C terminal domain that, when cleaved, becomes the 
ligand for Toll. Binding of cleaved Spätzle to the Toll receptor causes dimerization of the Toll receptor and phosphorylation of the intracellular Toll/interleukin-1 receptor (TIR) domain.

Recombinant Spätzle from P. chinensis was shown to upregulate the expression of the crustin 2 antimicrobial peptide when injected into the crayfish Procambarus clarkii (Shi et al., 2009). These authors also reported that transcription of Spätzle was up-regulated in response to inoculation with WSSV and the Gram-negative bacterium Listonella anguillarum. Li et al. (2010a) have also presented data on the transcription of Dorsal homologue, a member of the Rel/NF- $\mathrm{B}$ family of transcription factors in the Toll pathway, in the Chinese shrimp Penaeus chinensis. FcDorsal gene expression was shown to be modulated at different time points after injection of Gram-positive, Gram-negative and WSSV inoculates. Taken together, these observations suggested that the Spätzle/Toll pathway is important in the immune defence pathway of shrimp and crayfish. The recent study of Han-Ching Wang et al. (2010), however, demonstrated that the RNA inhibition (RNAi) of Toll transcription had no effect on survival to WSSV infection in the P. vannamei although did lead to an increase in shrimp mortality following infection with Vibrio harveyi, suggesting a role for the Toll receptor in response to Gram-negative bacterial infection but not in response to viruses. It is clear that the definitive role for decapod Toll in the detection of virallyassociated PAMPs awaits further clarification.

Definitive evidence for host transcribed receptors for viral PAMPs is in its infancy within the Crustacea. Recently, Sriphaijit et al. (2007) reported a serine protease from the shrimp Penaeus monodon that has high identity to a masquerade-like serine protease and which shows affinity for a metal-ion binding domain of yellow head virus (YHV). Sritunyalucksana et al. (2006) reported the constitutive expression of a homologue to a GTP-binding protein Rab7 in P. monodon (PmRab7) that is involved in the infection cycle of WSSV in this species. These reports provide exciting insights into the early interactions of these economically devastating viruses with host cells. More data on early host viral interaction will undoubtedly prove essential in identification of strategies for disease intervention within the context of aquaculture (discussed below).

Of great significance has been the identification of a family of transcriptionally variant Down Syndrome Cell Adhesion Molecule (DSCAM) receptors that were first identified in Drosophila melanogaster (Schmucker et al., 2000) and have since been characterized in the crustaceans Daphnia spp., Penaeus vannamei, P. monodon and Pacifastacus leniusculus (Brites et al., 2008; Chou et al., 2009; Chou et al., 2011; Watthanasurorot et al., 2011, respectively). Whilst initially DSCAM was reported to be involved in pathways of neuronal development during ontogeny in $D$. melanogaster (Schmucker et al., 2000), mRNA transcripts for DSCAM have been detected in the fat bodies of insects. Further, D. melanogaster DSCAM mutants have been shown to have impaired 
phagocytosis (Watson et al., 2005), leading to the hypothesis that this variable receptor family have a role in PAMP detection. To date, in all crustacean species except $P$.vannamei and $P$. monodon, these receptors have been characterised with transmembrane domains at the carboxy-terminus. In $P$. vannamei the receptor occurs as a soluble form (Chou et al., 2009) in the plasma whilst in the tiger shrimp P. monodon both cell surface and soluble forms of the DSCAM receptor have been reported (Chou et al., 2011). All crustacean DSCAM receptors have a conserved domain structure of 10 immunoglobulin-like (Ig) domains and six fribrinogen-like (FN) domains (Fig 1). In contrast to vertebrate DSCAM receptors that only have one variant expressed in each species, within the Arthropoda the domains Ig 2, Ig3 and Ig7 demonstrate extreme exon splice variation such that there are predicted to be more than 220000 different isoforms of the Pacifastacus leniusculus DSCAM, 13000 different isoforms in Daphnia spp. and, by comparison, 31000 different isoforms in the mosquito Anopheles gambiae. Whilst the definitive DSCAM ligands have yet to be determined in crustaceans, preliminary comparative in vivo experimental infections indicate that the sequence variation of the variable domains is altered by infection with different classes of PAMPs, including bacteria and viruses (Brites et al., 2008; Chou et al., 2009; Watthanasurorot et al., 2011). The extreme diversity of this family of receptors has been presented as a mechanism to provide a very high resolution PAMP recognition system within the invertebrates, which provides compelling support for concepts of specificity within the innate immune system of decapods.

\subsection{Cellular and non-cellular immune components}

Recognition of different PAMPs represents just the first step of an effective immune response. Indeed, for some commercially significant pathogens including the bacterium Aercococcus viridans var. homari and the parasitic dinoflagellate Hematodinium sp. unequivocal evidence for effective pathogen detection by the host does not exist. Never-the-less, post-recognition, central to the coordination of any downstream response are the haemocytes both circulating within the haemocoel and embedded within tissues. Crustacean haemocyte classification schemes have been variously described since the early studies of innate immunity in the 1980s (e.g. Söderhäll \& Smith, 1983; Tsing et al., 1989; Johansson et al., 2000; Söderhäll et al., 2003). As discussed most recently by Lin \& Söderhäll (2011) three classes of haemocyte can be identified in most crustaceans, including: hyaline cells (HC), semigranular haemocytes (SGH) and granular haemocytes (GH). HCs have a role in phagocytosis whilst SGHs have roles in encapsulation, early non-self recognition, melanisation and coagulation in most groups, but also phagocytosis in some species (e.g. Penaeus japonicus (Bachère, et al., 1995; Itami et al., 1998) and Macrobrachium rosenbergii (Sung et al., 2000)). GHs have functions of melanisation, produce and secrete antimicrobial peptides and are 
involved in cytotoxic reactions. SGHs and GHs undergo rapid degranulation reactions in the presence of PAMPs as described above. Evidence also indicates that the degranulation of SGH releases components including peroxinectin (Johansson et al., 1995) that trigger further degranulation. This positive feedback cascade has been presented as a mechanism of cell to cell communication within the innate immune system of crustaceans.

Degranulation of SGHs and GHs releases a battery of potent immune effector molecules into the circulation in the vicinity of the triggering PAMPs, perhaps the mostly widely studied being the zymogen prophenoloxidase (proPO) (reviewed in: Sritunyalucksana \& Söderhäll., 2000). Once activated, phenoloxidase catalyzes the oxidation of diphenols to quinones, representing a first step in the pathway of melanin formation. Melanin and intermediates in this pathway are known to be fungitoxic and fungistatic and melanisation of carapace wounds and invading bacteria and fungi is one characteristic pathology identified in crustaceans. The activation of prophenoloxidase itself represents that terminal step of the serine proteinase prophenoloxidase activating system (Wang et al., 2001; reviewed by Jiranvanichpaisal et al., 2006). Other proteins within the Crustacea have also been reported to have phenoloxidase-like activity. Of significance is the fact that the abundant respiratory pigment haemocyanin can be enzymatically cleaved to produce an enzyme with similar functionality to phenoloxidase (Adachi et al., 2003) meaning that there is an abundant pool of potential enzyme circulating within the haemolymph. Lee et al. (2003) have also shown that a cleaved carboxyl-terminal fragment of crayfish Pacifastacus leniusculus, haemocyanin, Astacidin 1, can act as antibacterial peptide with activity against Gram-positive and -negative bacteria.

As mentioned, concomitant to the release of prophenoloxidase from SGHs is the release of peroxinectin. Peroxinectin is a $\sim 76 \mathrm{kDa}$ cell adhesion molecule that also has functions as an opsonin and a peroxidase and stimulates the important haemocytic responses of phagocytosis and encapsulation by SGHs and HCs in decapods (Sritunyalucksana \& Söderhäll., 2000). Degranulation of SGHs and GHs also releases calcium dependent transglutaminases (TGases) which, in crayfish and shrimp, have been shown to be responsible for crosslinking the heterodimeric clotting protein stored in the plasma (Yeh et al., 1999; Sritunyalucksana \& Söderhäll., 2000). The clotting reaction is extremely rapid within decapods. This rapid response is essential to support organisms with a semi-closed circulatory system in which physical damage to appendages and the cuticle, through aggressive interactions and moulting, are not uncommon.

In addition to the suite of effector molecules described above, there is evidence that non-specific reactive molecules (e.g. superoxide radicals and nitrogen oxide) have a role within innate immune response of crustaceans. Respiratory burst and superoxide production accompanying phagocytosis was first reported in the shore crab (Bell \& Smith, 1993) but has since been recorded in penaeid 
shrimp (e.g. Guertler et al., 2010). The induction of inducible nitric oxide synthase (iNOS) has been reported in crustaceans in response to stimulation with 'non-self' particles, including LPS and laminarin or WSSV (Jiang \& Zhou, 2006). In Procambarus clarkii nitric oxide has been shown to be involved in the promotion of bacterial adhesion and to be produced during phagocytosis in Macrobrachium rosenbergii (reviewed in Rodriguez-Ramos et al., 2010).

\subsection{Stored and secreted antimicrobial peptides}

Haemocyte degranulation is known to release penaeidin antimicrobial peptides into the circulation of penaeid shrimp. Penaeidins are small peptides $(\sim 5-7 \mathrm{kDa})$ with characteristic amino-terminal cysteine rich and carboxy-terminal proline rich domains. Four classes, penaeidin $2-5$, are recognised and are produced and stored within the granules of GHs and SGHs (Tassanakajon et al., 2010) although isoform variants are recognised within this classification. Penaeidins have variously been reported to have activity against Gram-positive and Gram-negative bacteria, fungi and, in the case of Pen-5, WSSV (Woramongkolcha et al., 2011) (Table 1). Interestingly, in addition to direct antimicrobial effects, penaeidins have also been reported to have opsonic activity with shrimp (Cuthbertson et al., 2008).

Crustin antimicrobial peptides have been reported from a wider range of crustacean taxa than the penaeidins, including crabs and lobsters as well as shrimp (Smith et al., 2008). Crustins are also small peptides $(\sim 12 \mathrm{kDa})$ with a characteristic carboxy-terminal whey acidic protein (WAP) domain. Two main types of crustins have been proposed. Type 1 crustins, which phylogenetically group within the Pleocyemata and have a cysteine rich region positioned upstream of the WAP domain, and Type 2 crustins from shrimp that have an additional glycine rich domain 5'- of the cysteine rich region (Smith et al., 2008). Isoform variants are also recognised within this class structure (Vargas-Albores et al., 2004; Brockton et al., 2007). All full-length crustins have a signal sequence at the amino terminus indicating that, once produced within the granular haemocytes, they are secreted in to the plasma where they appear constitutively at high titre. Crustin antimicrobial peptides have been reported to have a role in the immune response to infection with Gram-positive and Gram-negative bacteria, fungi and viruses (Table 1) although many of these reports have only been based on studies of transcriptional regulation. Shockey et al. (2009) have also recently suggested that antimicrobial activity might be an indirect effect and that crustins may serve as opsonic factors like the penaeidins.

A second group of secreted antimicrobial immune effectors reported within the Crustacea is the Anti-Lipopolysaccharide Factors (ALFs). ALFs are small basic proteins which bind lipopolysaccharide and have strong antibacterial activity against, in particular, Gram-negative 
bacteria but also activity against Gram positive bacteria and fungi (Table 1; De la Vega et al., 2008). Also, it has been reported from RNA inhibition (RNAi) studies of ALF transcription in Pacifastacus leniusculus haemopoeitic tissue cell culture that ALFs may act by directly interfering with viral replication (Liu et al., 2006).

However, as discussed further below, the reported broad and perhaps conflicting spectrum of activity of different classes of antimicrobial peptide may, in part, be confounded by the use of in vitro methods in isolation to determine activity. Further, the apparent in vitro activity recorded for some peptides may actually represent an artefact of the biochemical nature of these small, often cationic, molecules.

\subsection{Developments in our understanding of host:virus interactions.}

Published studies of specific host:virus interactions initially lagged behind our early understanding of crustacean immunology. None-the-less, whilst it is true that definitive and explicit immune responses to viral infection broadly remain to be resolved for the wider Decapoda, rapid progress has been made in the study of shrimp:virus interactions. These developments have been recently and comprehensively reviewed by Liu et al. (2009) and Flegel \& Sritunyalucksana (2011). As summarised above, roles for antimicrobial peptides have been inferred from studies of transcriptional regulation of gene expression but, and as elaborated below, in isolation these cannot be considered as positive proof of a role in antiviral immunity. One area of research interest explored in virus shrimp models is the role of apoptosis in regulating virus replication. For example: histopathological evidence, including pyknosis and karyorrhexis, of viral induced apoptosis has been provided in the case of Penaeus mondon infected with the lethal virus YHV (Khanobdee et al., 2002) and this has subsequently been supported by transcriptional evidence for the down-regulation of the P. monodon Defender against Apoptotic Death 1 (DADl) gene in shrimp infected with YHV (Moltathong et al., 2008). In contrast, P. monodon is also a carrier for IHHNV, which causes Runt Deformity Syndrome (RDS) in $P$. vannamei but shows limited pathology in $P$. monodon. Chayaburakul et al. (2005) have reported that apoptosis of $P$. monodon lymphoid cells infected with IHHNV may represent a mechanism to restrict viral replication and proliferation of disease and have presented this as a case of host mediated viral immunity. It is clear from these different reports that, as is the case bacterial and fungal pathogens, there is no single model to describe host viral interactions and that the response to any one virus is undoubtedly species- (host and virus) and strain-specific. 
In summary, the induction of an effective immune response is most often associated with anything from a localized to systemic degranulation response which releases a suite of potent effector molecules into the plasma. Once activated these components act to stimulate the phagocytosis or encapsulation and melanisation of invading pathogens. Encapsulated pathogens are cleared from the circulation, often collecting in the gills or hepatopancreas, whereupon they are broken down. Associated with this is often a dramatic decline in the number of freely circulating haemocytes, a haemocytopenia which is rectified within 24-48 hours (Smith \& Ratcliffe, 1980). Proliferation of new haemocytes has been shown to take place within the haemopoeitic tissues of crustaceans and to be the result of astakine peptides abrogating the suppression of haemopoeisis by transglutaminases (Lin \& Söderhäll, 2011). There is also evidence from crabs (e.g. Carcinus maenas and Hyas arenarius; Hammond \& Smith (2002); Roulston \& Smith (2011), respectively) and shrimp (P. japonicus; Sequeira et al., 1996) for the proliferation of new haemocytes within the haemolymph.

\section{Existing prophylactic treatments of crustacean disease based on current knowledge}

In the preceding discussion a brief overview of current knowledge of the immune response in commercially important crustaceans has been provided. Whilst the details of many pathways, and how they inter-relate, are still unknown these limited data have provided a basis from which attempts have been made to combat disease within crustacean aquaculture by prophylaxis. The intention here has been to augment the innate immune response prior to actual pathogen exposure. Efforts have focussed on exposing the host to a variably-characterised PAMP with the goal of stimulating or triggering an immune response in the host species. For example, Vici et al. (2000) reported the use 'bacterin' (formalin-inactivated Vibrio or Photobacterium bacteria) and yeast (Acremonium dyosporii) preparations mixed with feed and administered orally to larvae of Macrobrachium rosenbergii whilst Campa-Córdova et al. (2002) reported the use of $\beta-1,6$ glucans isolated from Saccharomyces cerevisiae, sulphated polysaccharides from Cyanothece sp., or $\beta-1,3$ glucans from Laminaria digitata for bath immersion of white shrimp Penaeus vannamei.

The success or otherwise of a treatment has nearly always been measured in terms of an increase in the activity of phenoloxidase or other immune 'proxy', e.g. the titre of superoxide anions or activity of the superoxide dismutase enzyme, or an increase in the transcriptional activity of a related gene. The merits and limitations of this approach have been broadly discussed previously (Smith et al., 2003) and will not be repeated in full here. However, to summarise, it is widely accepted that the innate immune response of invertebrates is sensitive and potent but that some of the components and mechanisms, including respiratory burst, are not pathogen specific. It has been predicted that the activation pathways might be closely regulated to prevent the inappropriate triggering of an 
immune response, and this has indeed been shown, for example, by the characterization of multiple control pathways including that of the pacifastin inhibitor (Simonet et al., 2003). The inappropriate triggering of an immune response, which includes the potential degranulation of circulating haemocytes, may at worst lead to host tissue damage (Lorenzon et al., 1999; Xian et al., 2009) or, at the very least, will constitute an energetic cost to the host. Examples for physiological costs of an immune response, such as through repeated immunostimulation, have been reported within the literature, including cases in crustaceans and insects (e.g. reviewed by Smith et al., 2003; see also: Christensen et al., 2005; Hauton et al., 2007).

Based on our current understanding of immune response in decapod crustaceans the prophylactic artificial application of various, and often poorly characterised, PAMPs as a means to protect species within aquaculture is as a blunt approach that is very unlikely to serve as a global solution to the problems of commercially significant diseases. In the long term, and as a contribution to global food security, effective disease therapies must be developed through an improved and detailed understanding of immune pathways and associated immune surveillance mechanisms within these host groups.

\section{Directions for future research}

Current approaches to the prophylactic treatment of disease within crustacean aquaculture should be superseded by new strategies that are based on a more complete understanding of the complexity of the immune response within the Decapoda. The goal should be to manipulate the immune system in a calculated way so as to avoid triggering localised and/or systemic haemocyte degranulation or the inappropriate activation of cascades leading to the release of toxic but non-specific immune effectors. Five aspects of the crustacean immune system clearly warrant focussed research effort and these include methods to influence the number and/or type of circulating blood cells or increasing the titre of specific antimicrobial peptides. In the case of capture fisheries, where the potential for direct intervention in disease cycles or host response is unrealistic, a more detailed knowledge of the invertebrate immune response might be used to identify informative markers of immune performance that could be used to select immunocompetent individuals and populations as broodstock for restocking or ranching (Aleivar-Warren, 2001; Lightner, 2005). These approaches will become increasingly important to ensure the continuation of sustainable fisheries in a 'future ocean' affected by climate change and modified pathogen ranges (reviewed elsewhere in this volume; see also: Drew Harvell et al., 2002; Ford \& Smolowitz, 2007). 


\subsection{The diversity of potential immune receptors and regulatory pathways}

From the discussion of section 2 it is clear that a rapidly expanding number of PRP families and associated regulatory pathways are being described in crustaceans. However, for many of these receptors the respective ligand or ligand complexes are yet to be resolved. Within this broad spectrum of receptor families there is considerable scope for generating specific responses to different types of pathogen and this is exemplified by the growing list of transcriptionally-variant DSCAM receptors that are being identified. Clearly, future efforts should consider that the range of cell surface expressed proteins exploited by pathogens for entry may be much greater than those classically considered as PRPs; we are certainly not yet at a stage where research efforts can be focussed or rationalized.

Identification of novel receptor families and the resolution of receptor specificity and downstream pathways may assist in the more focussed design of intervention strategies for a number of key pathogens, including viruses, within the context of aquaculture. As Sritunyalucksana et al. (2006) have already shown in vivo, antibody-neutralization of the PmRab7 receptor can reduce mortality after infection with WSSV in P. monodon. Further support for the concept of interference of viral binding to host cell surface receptors comes from data that show that mortality from WSSV in the shrimp $P$. monodon and $P$. vannamei can be reduced by prior inoculation with recombinant viral coat proteins (Witteveldt et al., 2004; 2006). These reports present an extremely promising method with which to target infection by specific viral pathogens although many challenges do remain. For example, the identification of a cost-effective and realistic (i.e. dietary) delivery mechanism and the farm-scale empirical characterization of the kinetics and longevity of protective effect will need to be confirmed for every respective treatment.

\subsection{Antimicrobial peptides}

A second avenue of promise is the refined/hypothesis testing study of the growing number of putatively characterized antimicrobial peptides. The attraction of antimicrobials is the apparent lack of activity against crustacean host tissues. Currently however, the spectrum of antimicrobial activity of each peptide class appears broad but somewhat conflicted (Table 1) and a concerted effort is needed to confirm and/or resolve existing observations. For example, the apparent dominance of peptides with activity against Gram-positive bacteria is counter-intuitive within a marine context and raises the possibility that some peptides have an alternate function such as acting as an opsonin (reviewed in Cuthbertson et al., 2008). Alternatively, as argued by Shockey et al. (2009), some recorded activities could represent an aberration resulting from in vitro work with recombinant or purified peptides. Progress would best be made by employing in vivo techniques in addition to 
studies of transcriptional regulation post challenge. mRNA transcription is not definitive proof of activity and confirmatory hypothesis-testing studies using RNAi would present one solution to this uncertainty. In vivo RNAi to knock-down host antimicrobial gene expression before pathogen challenge has already provided exciting insights into possible alternate functions for some of the identified peptides, including acting as opsonic factors (Shockey et al., 2009). RNAi presents a useful initial test of the potential in vivo mechanism or spectrum that could be confirmed using techniques such as antibody inhibition and immunolabelling (e.g. Destoumieux et al., 2000).

Ultimately however, whilst the genetic modification (GM) of aquaculture crops remains publically unsupported the 'development' of GM crustacean lines that are engineered to over-express particular peptides remains non-viable. However, it is possible that the complement of antimicrobial peptides (class and isoforms) and relative expression levels could be used as markers of immune function to select for preferred breeding lines or individuals and populations that show a favourable immune phenotype (e.g. Hauton et al., 2007). The selection of favourable lines through breeding could also have application within the context of aquaculture and in the restocking or ranching for wild fisheries (de Lorgeril et al., 2008). Alternatively, structural comparison of different isoforms or classes might lead to the identification of core peptide sequences that are essential for antimicrobial effect and raises the possibility of the development of the oral delivery of synthetic refractory peptides as a novel form of prophylaxis in aquaculture (Kloczewiak et al., 1994; Cuthbertson et al., 2006; Cuthbertson et al., 2008).

\subsection{Haemocyte proliferation and maturation in vivo}

Resolution of the in vivo proliferation of haemocyte classes has proved challenging and, even today, the relative dominance of proliferation within the haemopoeitic tissues versus proliferation within the circulation remains uncertain. However, recent studies in this area have made important steps forward, including identifying some of the molecular controls on the commitment of haemocyte stem cells in crayfish and their subsequent differentiation into the different classes of haemocyte (Lin \& Söderhäll, 2011). Detailed knowledge of these pathways may identify key factors that regulate proliferation in vivo. For example, Lin \& Söderhäll (2011) have demonstrated that the transcription of astakine 1 gene has a diel rhythm such that it is highly expressed after dark incubation, from which the authors concluded that haemocyte proliferation would be at its greatest in the hours of morning. Data such as these could be used to identify ways to manipulate the environment to avoid diel, seasonal or moult stage related suppression of haemopoeisis in aquaculture species. At a fundamental level too, by manipulating the environment to increase the number of circulating haemocytes there is also the potential to increase the immune capacity of the 
host, without causing unwanted haemocyte degranulation and the concomitant release of potent but non-specific immune effectors. A caveat is that enhanced haemocyte proliferation would undoubtedly constitute an energetic cost to the cultured individual and this would probably need to be accommodated by dietary supplementation within the context of aquaculture.

\subsection{The importance of gut immunity}

The crustacean midgut, along with the gills, represents an extremely important route of infection in crustaceans. For example, infections with Vibrio harveyi are known to cause extensive pathology and tissue inflammation in the gut and hepatopancreas in shrimp (Jiranvanichpaisal et al., 2010) and the gut is an area of localised changes in gene expression following infection (Soonthornchai et al., 2010). As recently described by Passarelli \& Hall (2011) the midgut epithelia is also exploited by insect baculoviruses to escape from the midgut environment before removal by host epithelial cell sloughing. Knowledge of crustacean gut immunity is very limited, in part because of the dominant focus on the haemolymph and haemocytes as the main site of immune reactivity. A more detailed understanding of the physiology and immune capacity of the gut is necessary, especially in light of: 1) it being a key site for pathogen uptake, 2) it playing an important role in the oral administration of any prophylactics (e.g. application of stimulants, RNAi triggers or nucleic acid based recombinant viral coat proteins and antibodies to viral receptors), 3) the interest in the application of probiotics to promote health in cultured species (Verschuere et al., 2000), and 4) the rapid progress made with regard to the importance of gut immunity for regulating nutrition and disease in other vertebrate and invertebrate taxa (e.g. see Riddell et al., 2011 and reviews by Fortun-Lamothe \& Boullier, 2007; Gomez \& Balcazar, 2008; Fukatsu \& Kudsk, 2011). From example Anthony et al. (2011a) report that penaeidin-3 gene expression is upregulated in the gut of Penaeus monodon following administration of a Bacillus probiotic; should this be viewed as a beneficial mechanism of immune protection or simply the shrimp reacting predictably to an increased level of bacteriallyassociated PAMPs taken up from the gut? It is clear that we are still some distance from understanding the role of different antimicrobial peptides, which exhibit diverse activities, in different tissues during the time course of an infection and this emphasizes the need to consider the augmentation of immune responses in the gut and other epithelia, in addition to the conventionally studied haemolymph compartment, in assessing the benefit of a probiotic or PAMP-associated strategy for disease mitigation.

\subsection{Host-virus interactions}


One exciting area of research that warrants continued and concerted effort is the interaction between competing viruses and also of viral genes and genome fragments within the host cells, not least because of the predominance of viral disease within shrimp aquaculture. Within shrimp species several groups have reported that pre-infection with one particular virus can reduce mortality associated with the later exposure to a second more virulent virus. For example: Tang et al. (2003) reported that prior infection with IHHNV improved the survival of the blue shrimp Penaeus stylirostris to subsequent infection with WSSV and similar interactions have now been described for these two viruses in the white shrimp P. vannamei (Bonnichon et al., 2006). Indeed, in vitro studies using mosquito C6/36 cell lines serially infected with densovirus (Burivong et al., 2004) and the same cells preinfected with densovirus and then Dengue virus (Kanthong et al., 2008) indicate that competitive interactions in the replication of viral genomes might be widespread. This idea of 'viral interference' is not new; Fenner (1974) first defined this term to explain the competition between co-infecting viruses for the limited replication resources provided by the host cell. Furthermore, defective interfering particles (DIPs), which are formed as a result of replication errors within the host cell, can result in genome deletions within the replicated viral genomes. Deletions in genome length mean that these non-coding fragments can be replicated more rapidly and become enriched, as identified for the poliovirus by Cole and Baltimore (1973). Theoretically, the replication of DIPs may ultimately lead to a low level of fluctuating wild-type viremia (Frank, 2000), a situation which has been reported in penaeid shrimp (Tsai et al., 1999; Flegel et al., 2004). The replication of viruses in crustacean species has also been shown to be affected by the presence of incomplete viral ORFs persistently occurring within the host genome of some shrimp. For example: Tang \& Lightner (2006) reported several instances in which IHHNV-related sequences have been found within the genomes of P. monodon in Africa and Australia. That incomplete viral ORFs have been shown to be present within the genomes of certain species, populations or lines of crustaceans and are transcribed and interfere with successful viral replication, as developed in the theory of 'viral accommodation' (see Flegel \& Sritunyalucksana, 2011), is compelling and extremely significant. These data also obviously present a challenging impediment to the unambiguous study of host/viral interactions where different research groups inevitably have used different strains of both host and virus for study. Advances in this field are being rapidly reported and, undoubtedly, developments in this area will continue to provide important insights in to the mechanisms of host/viral and viral/viral interactions within the context of crustacean aquaculture.

\section{Practical challenges to future study}


From the above discussion it is fair to conclude that very significant advances have been made recently in our understanding of crustacean immunology. However, impediments to progress do exist. From a research standpoint the lack of an immortal crustacean cell line represents a significant impediment to progress. Research in crustacean immunity, and in particular host/virus interactions, has always trailed that of advances in our understanding of insect immunology. In part this is attributable to the early development of permanent cell lines for insects. Whilst recent significant progress has been made in sustaining primary cultures of crustacean haemocytes and ovarian cells (George \& Dhar, 2010) this does not offer the utility of an immortal cell line. Intensive efforts directed toward this issue are certainly warranted.

Even with technical developments such as the establishment of a permanent crustacean cell line, additional challenges to the development of practical 'immunity-informed' methods for disease control will remain. For example, a paucity of genomic sequence data for many commercially important or model crustacean hosts represents a significant impediment to research. Progress has been made with the publication of the complete genome libraries for daphnid water fleas (www.wfleabase.org) and an increasing number of published crustacean EST libraries. However, without the further development of annotated genomic resources for some key commercial and model decapod crustaceans (e.g. penaeid shrimp, nephropid lobsters, and portunid crabs) the full insight offered by powerful molecular tools such as microarrays and high-throughput sequencing (HTS) will remain unrealised.

Furthermore, whilst most diseases are known from the context of aquaculture, some commerciallysignificant disease causing pathogens occur in wild populations (e.g. Aerococcus viridans var. homari and Hematodinium spp.). In almost all cases it is very unlikely that intervention and control strategies, such as treatment by prophylaxis, will be applicable in these cases. For wild populations alternative management approaches will be need to be considered, including for example breeding from resistant lines to restock or ranch local fisheries. Within the context of wild fisheries another significant complication arises from the issue of climate change, which will affect the physiology of both hosts and pathogens as implied in the concept of the 'disease triad' postulated by Sniezsko (1974). Improved knowledge of the effects of environmental change on the immune performance of invertebrates and the spread or movement of pathogens will undoubtedly inform management practices, as has already been seen in part for the native oyster (Crassostrea virginica) industry in the eastern United States (Hoffman et al., 1995; Powell et al., 1996).

Even within the context of an environmentally regulated culture facility however, the stress associated with holding organisms at artificially high densities combined with the challenges of ensuring integral biosecurity means that periodic outbreaks of infectious disease are likely to 
continue. It is unlikely that there is a single 'magic bullet' in the immune system to control disease and so any measures to promote immune protection must be seen as part of a holistic approach to disease control that would include appropriate biosecurity and a balanced management strategy to achieve a sustainable economic return from a crop whilst minimising the occurrence of significant disease outbreaks.

\section{Summary}

This is undoubtedly an exciting time in the field of invertebrate immunology. New discoveries of PRPs, immune effectors and regulatory pathways are offering fundamental new insights in our efforts to understand disease in cultured populations and also to develop knowledge of environmental effects on host/pathogen interactions within a fishery context. The pace at which new discoveries are reported has increased in the past ten years and the number of research groups around the world with expertise in this field has increased dramatically. In part this underlines the importance of the crustacean industry in meeting the demands for sustainable global food security. As discussed, challenges do remain but with the use of more insightful technologies, such as proteomic methods, HTS and the use of RNAi to experimentally manipulate and test hypotheses, the speed at which some of these challenges are resolved will accelerate.

\section{Acknowledgements:}

The author would like to acknowledge the generous financial support of the OECD in presenting this manuscript.

\section{References}

Adachi, K., Hirata, T., Nishioka, T., Sakaguchi M., 2003. Hemocyte components in crustaceans convert hemocyanin into a phenoloxidase-like enzyme. Comparative Biochemistry and Physiology Part B 134, 135-141.

Aleivar-Warren, A., 2001. ShrimpMap: A genetic approach to understand immune response and disease resistance in shrimp. In: Browdy, C.L., Jory, D.E. (eds) New Wave Proceedings of the Special Session on Sustainable Shrimp Farming, BATON ROUGE, L.A. 238-253.

Amparyup, P., Imjongjirak, C., Tassanakajon, A., 2011. Molecular cloning, genomic organization and antibacterial activity of a second isoform of antilipopolysaccharide factor (ALF) from the mud crab, Scylla paramamosain. Fish and Shellfish Immunology 30, 58-66. 
Antony, S.P., Bright Singh, I.S., Jose, R.M., Anil Kumar, P.R., Philip, R., 2011a. Antimicrobial peptide gene expression in tiger shrimp, Penaeus monodon in response to gram-positive bacterial probionts and white spot virus challenge. Aquaculture 316, 6-12.

Antony, S.P., Singh, I.S.B., Sudheer, N.S., Vrinda, S.,Priyaja, P., Philip, R., 2011b. Molecular characterization of a crustin-like antimicrobial peptide in the giant tiger shrimp, Penaeus monodon, and its expression profile in response to various immunostimulants and challenge with WSSV. Immunobiology 216, 184-194.

Arts, J.A., Cornelissen, F.H.J., Cijsouw, T., Hermsen, T., Savelkoul, H.F., Stet, R.J., 2007. Molecular cloning and expression of a Toll receptor in the giant tiger shrimp, Penaeus monodon. Fish and Shellfish Immunology 23, 504-513.

Bachère, E., Miahle, E., Rodriguez, J., 1995. Identification of defence effectors in the haemolymph of crustaceans with particular reference to the shrimp Penaeus japonicus (Bate), prospects and applications. Fish and Shellfish Immunology 5, 597-612.

Battison, A.L., Summerfield, R., Patrzykat, A., 2008. Isolation and characterisation of two antimicrobial peptides from haemocytes of the American lobster Homarus americanus. Fish and Shellfish Immunology 25, 181-187.

Bell, K.L., Smith, V.J., 1995. Occurrence and distribution of antioxidant enzyme activity in the blood of Carcinus maenas. Marine Biology 123, 829-836.

Belvin, M.P., Anderson, K.V., 1996. A conserved signalling pathway: the Drosophila Toll-dorsal pathway. Annual Review of Cell and Developmental Biology 12, 393-416.

Bonnichon, V., Lightner, D.V., Bonami, J.-R., 2006. Viral interference between infectious hypodermal and hematopoietic necrosis virus and white spot syndrome virus in Litopenaeus vannamei. Diseases of Aquatic Organisms 72, 179-184.

Brites, D., McTaggart, S., Morris, K., Anderson, J., Thomas, K., Colson, I., Fabbro, T., Little, T.J., Ebert, D., Du Pasquier, L., 2008. The Dscam homologue of the crustacean Daphnia is diversified by alternative splicing like in insects. Molecular Biology and Evolution 25, 1429-1439.

Brockton, V., Hammond, J.A., Smith, V.J., 2007. Gene characterisation, isoforms and recombinant expression of Carcinin, an antibacterial protein from the shore crab, Carcinus maenas. Molecular Immunology 44, 943-949.

Burivong, P., Pattanakitsakul, S.-N., Thongrungkiat, S., Malasit, P., Flegel, T.W., 2004. Markedly reduced severity of Dengue virus infection in mosquito cell cultures persistently infected with Aedes albopictus densovirus (AalDNV). Virology 329, 261- 269. 
Campa-Córdova, A.I., Hernández-Saavedra, N.Y., De Philippis, R., Ascencio, F., 2002. Generation of superoxide anion and SOD activity in haemocytes and muscle of American white shrimp (Litopenaeus vannamei) as a response to $\beta$-glucan and sulphated polysaccharide. Fish Shellfish Immunology 12, 353-366.

Chayaburakul, K., Lightner, D.V., Sriurairattana, D., Tang Nelson, K., Withyachumnarnkul, B., 2005. Different responses to infectious hypodermal and hematopoietic necrosis virus (IHHNV) in Penaeus monodon and P. vannamei. Diseases of Aquatic Organisms 67, 191-200.

Chen, J.Y., Pan, C.Y., Lin, T.L., Lin, C.H., 2009. In vitro activities of three synthetic peptides derived from epinecidin-1 and an anti-lipopolysaccharide factor against Propionibacterium acnes, Candida albicans, and Trichomonas vaginalis. Peptides 30, 1058-1068.

Chintapitaksakul, L., Udomkit, A., Smith, D.R., Panyim, S., Sonthayanon, B., 2008. Expression analysis of selected haemocyte transcripts from black tiger shrimp infected with yellow head virus. ScienceAsia 34, 327-333.

Chiou, T.T., Wu, J.L., Chen, T.T., Lu, J.K., 2005. Molecular cloning and characterization of cDNA of penaeidin-like antimicrobial peptide from tiger shrimp (Penaeus monodon). Marine Biotechnology 7, 119-127.

Chou, P.-H., Chang, H.-S., Chen, I.-T., Lin, H.-Y., Chen, Y.-M., Yang, H.-Y., Wang, K.C., 2009. The putative invertebrate adaptive immune protein Litopenaeus vannamei Dscam (LvDscam) is the first reported Dscam to lack a transmembrane domain and cytoplasmic tail. Developmental and Comparative Immunology 33, 1258-1267.

Chou, P.-H., Chang, H.-S., Chen, I.-T., Lee, C.-W., Hung, H.-Y., Wang, K.C., 2011. Penaeus monodon Dscam (PmDscam) has a highly diverse cytoplasmic tail and is the first membranebound shrimp Dscam to be reported. Fish and Shellfish Immunology 30, 1109-1123.

Christensen, B.M., Li J., Chen, C.-C., Nappi, A.J., 2005. Melanization immune responses in mosquito vectors. TRENDS in Parasitology 21, 192-199.

Cole, C.N., Baltimore, D., 1973. Defective interfering particles of poliovirus. 3. interference and enrichment. Journal of Molecular Biology 76, 345-361.

Cuthbertson, B.J., Büllesbach, E.E., Gross, P.S., 2006. Discovery of synthetic penaeidin activity against antibiotic-resistant fungi. Chemical Biology and Drug Design 68, 120-127.

Cuthbertson, B.J., Deterding, L.J., Williams, J.G., Tomer, K.B., Etienne, K., Blackshear, P.J., Büllesbach, E.E., Gross, P.S., 2008. Diversity in penaeidin antimicrobial peptide form and function. Developmental and Comparative Immunology 32, 167-181. 
de la Vega, E., O’Leary, N.A., Shockey, J.E., Robalino, J., Payne, C., Browdy, C.L., Warr, G.W., Gross, P.S., 2008. Anti-lipopolysaccharide factor in Litopenaeus vannamei (LvALF): A broad spectrum antimicrobial peptide essential for shrimp immunity against bacterial and fungal infection. Molecular Immunology 45, 1916-1925.

de Lorgeril, J., Gueguen, Y., Goarant, C., Goyard, E., Mugnier, C., Fievet, J., Piquemal, D., Bachère., E. 2008. A relationship between antimicrobial peptide gene expression and capacity of a selected shrimp line to survive a Vibrio infection. Molecular Immunology 45, 3438-3445.

Destoumieux, D., Bulet, P., Strub, J.-M., Bachère, E. 1999. Recombinant expression and range of activity of penaeidins, antimicrobial peptides from penaeid shrimp. European Journal of Biochemistry 266, 335-346.

Destoumieux, D., Muñoz, M., Cosseau, C., Rodriguez, J., Bulet, P., Comps, M., Bachère, E., 2000. Penaeidins, antimicrobial peptides with chitin-binding activity, are produced and stored in shrimp granulocytes and released after microbial challenge. Journal of Cell Science, 113: 461-469.

Drew Harvell, C., Mitchell, C.E., Ward, J.R., Altizer, S., Dobson, A.P., Ostfeld, R.S., Samuel, M.D., 2002. Climate warming and disease risks for terrestrial and marine biota. Science 296, 2158-2162.

Fenner, F., McAuslan, B.R., Mims, C.A., Sambrook, J., White, D.O., 1974. The Biology of Animal Viruses, 2nd edition. Academic Press New York NY 834pp.

Flegel, T.W., Nielsen L., Thamavit, V., Kongtim, S., Pasharawipas, T., 2004. Presence of multiple viruses in non-diseased cultivated shrimp at harvest. Aquaculture 240, 55-68.

Flegel, T.W., Sritunyalucksana, K., 2011. Shrimp Molecular Responses to Viral Pathogens. Marine Biotechnology 13, 587-607.

Ford, S.E., Smolowitz, R., 2007. Infection dynamics of an oyster parasite in its newly expanded range. Marine Biology 151, 119-133.

Fortun-Lamothe, L., Boullier, S., 2007. A review on the interactions between gut microflora and digestive mucosal immunity. Possible ways to improve the health of rabbits. Livestock Science 107, 1-18.

Frank, S.A., 2000. Within-host Spatial Dynamics of Viruses and Defective Interfering Particles. Journal of Theoretical Biology. 206, 279-290.

Fukatsu, K., Kudsk, K., 2011. Nutrition and gut immunity. The Surgical Clinics of North America 91, 755-770. 
Garcia, J.C., Reyes, A., Salazar, M., Granja, C.B. 2009. Differential gene expression in White Spot Syndrome Virus (WSSV)-infected naive and previously challenged Pacific white shrimp Penaeus (Litopenaeus) vannamei. Aquaculture 289, 253-258.

George, S.K., Dhar, A.K., 2010. An improved method of cell culture system from eye stalk, hepatopancreas, muscle, ovary, and haemocytes of Penaeus vannamei. In Vitro Cell and Developmental Biology - Animal 46, 801-810.

Gomez G.D., Balcazar, J.L., 2008. A review on the interactions between gut microbiota and innate immunity of fish. FEMS Immunology and Medical Microbiology 52, 145-154.

Guertler, C., Schleder, D.D., Barracco, M.A., Perazzolo, L.M., 2010. Comparative study of the intracellular superoxide anion production in different penaeid species through the NBT-reduction assay. Aquaculture Research 41, 1082-1088.

Hammond, J.A., Smith, V.J., 2002. Lipopolysaccharide induces DNA-synthesis in a sub-population of hemocytes from the swimming crab, Liocarcinus depurator. Developmental and Comparative Immunology 26, 227-236.

Han-Ching Wang, K.C., Tseng, C.-W., Lin, H.-Y., Chen, I.-T., Chen, Y.-H., Chen, Y.-M., Chen, T.-Y., Yang, H.-L., 2010. RNAi knock-down of the Litopenaeus vannamei Toll gene (LvToll) significantly increases mortality and reduces bacterial clearance after challenge with Vibrio harveyi. Developmental and Comparative Immunology 34, 49-58.

Hauton C., Brockton, V., Smith, V.J., 2007. In vivo effects of immunostimulants on gene expression and disease resistance in lobster (Homarus gammarus) post-larval stage VI (PLVI) juveniles. Molecular Immunology 44: 443-450.

Hoffmann, E.E., Powell, E.N., Klinck, J.M., Saunders, G., 1995. Modelling diseased oyster populations: 1 modelling Perkinsus marinus infection in oysters. Journal of Shellfish Research 14, 121-151.

Ho, S.H., Chao, Y.C., Tsao, H.W., Sakai, M., Chou, H.N., Song, Y.L., 2004. Molecular cloning and recombinant expression of tiger shrimp Penaeus monodon penaeidin. Fish Pathology 39, 15-23.

Itami, T., Asano, M., Tokushige, K., Kubono, K., Nakagawa, A., Takeno, N., Nishimura, H., Maeda, M., Kondo, M., Takahashi, Y., 1998. Enhancement of disease resistance of kuruma shrimp, Penaeus japonicus, after oral administration of peptidoglycan derived from Biifidobacterium thermophilium. Aquaculture 164, 277-288.

Itami, T., Mekata, T., Sudhakaran, R., Okugawa, S., Kono, T., Sakai, M., 2010. Molecular cloning and transcriptional analysis of a newly identified anti-lipopolysaccharide factor gene in kuruma shrimp, Marsupenaeus japonicus. Letters in Applied Microbiology 50, 112-119. 
Janeway, C.A., Medzhitov R., 2002. Innate immune recognition. Annual Reviews in Immunology 20, 197-216.

Jiang, G., Yu, R., Zhou, M., 2006. Studies on nitric oxide synthase activity in haemocytes of shrimps Fenneropenaeus chinensis and Marsupenaeus japonicus after white spot syndrome virus infection. Nitric Oxide 14, 219-227.

Jiravanichpaisal, P., Luel L.B., Söderhäll, K., 2006. Cell-mediated immunity in arthropods: Hematopoiesis, coagulation, melanization and opsonisation. Immunobiology 211, 213-236. Jiravanichpaisal P., Söderhäll, K., Söderhäll, I., 2010. Inflammation in Arthropods. Current Pharmaceutical Design 16, 4166-4174.

Johansson, M.W., Keyser, P., Sritunyalucksana, K., Söderhäll, K., 2000. Crustacean haemocytes and haematopoiesis. Aquaculture 191, 45-52.

Johansson, M.W., Lind, M.I., Holmblad, T., Thornqvist, P.O., Söderhäll, K., 1995. Peroxinectin, a novel cell adhesion protein from crayfish blood. Biochemical and Biophysical Research Communications 216, 1079-1087.

Kang, C.J., Xue, J.F., Liu, N., Zhao, X.F., Wang, J.X., 2007. Characterization and expression of a new subfamily member of penaeidin antimicrobial peptides (penaeidin 5) from Fenneropenaeus chinensis. Molecular Immunology 44, 1535-1543.

Kanthong, N., Khemnu, N., Sriurairatana, S., Pattanakitsakul, S.-N., Malasit, P., Flegel, T.W., 2008. Mosquito cells accommodate balanced, persistent co-infections with a densovirus and Dengue virus. Developmental and Comparative Immunology 32, 1063-1075.

Khanobdee, K., Soowannayan, C., Flegel, T.W., Ubo, S., Withyachumnarnkul, B., 2002. Evidence for apoptosis correlated with mortality in the giant black tiger shrimp Penaeus monodon infected with yellow head virus. Diseases of Aquatic Organisms 48, 79-90.

Kloczewiak, M., Black, K.M., Loiselle, P., Cavaillon, J.M.,Wainwright, N., Warren, H.S., 1994. Synthetic peptides that mimic the binding-site of horseshoe-crab antilipopolysaccharide factor. Journal of Infectious Diseases 170, 1490-1497.

Kono, T., Sonoda, K., Kitao, Y., Mekata, T., Itami, T., Sakai, M., 2009. The expression analysis of innate immune-related genes in Kuruma shrimp Penaeus japonicus after DNA vaccination against penaeid rod-shaped DNA virus. Fish Pathology 44, 94-97.

Lee, S.L., Lee B.L., Söderhäll, K., 2003. Processing of an antibacterial peptide from hemocyanin of the freshwater crayfish Pacifastacus leniusculus. The Journal of Biological Chemistry 278, 79277933. 
Lee S.Y., Wang, R.G., Söderhäll, K., 2000. A lipopolysaccharide- and beta-1,3-glucan-binding protein from hemocytes of the freshwater crayfish Pacifastacus leniusculus - Purification, characterization, and cDNA cloning. Journal of Biological Chemistry 275, 1337-1343.

Li, F., Wang, D., Li, S., Yan, H., Zhang, J., Wang, B., Zhang, J., Xiang, J., 2010a. A Dorsal homolog (FcDorsal) in the Chinese shrimp Fenneropenaeus chinensis is responsive to both bacteria and WSSV challenge. Developmental and Comparative Immunology 34, 874-883.

Li, C.Y., Yan, H.Y., Song, Y.L., 2010b. Tiger shrimp (Penaeus monodon) penaeidin possesses cytokine features to promote integrin-mediated granulocyte and semi-granulocyte adhesion. Fish and Shellfish Immunology 28, 1-9.

Lightner, D.V., 2005. Biosecurity in shrimp farming: Pathogen exclusion through the use of SPF stock and routine surveillance. Journal of the World Aquaculture Society 36, 229-248.

Lin, X., Söderhäll, I., 2011. Crustacean hematopoeisis and the astakine cytokines. Blood 117, 64176424.

Liu, H., Jiravanichpaisal, P., Söderhäll, I., Cerenius, L., Söderhäll, K., 2006.

Antilipopolysaccharide factor interferes with White Spot Syndrome Virus replication in vitro and in vivo in the crayfish Pacifastacus leniusculus. Journal of Virology 80, 10365-10371

Liu, H., Söderhäll, K., Jiravanichpaisal, P., 2009. Antiviral immunity in crustaceans. Fish and Shellfish Immunology 27: 79-88.

Liu, H., Wu, C., Matsuda, Y., Kawabata, S.-I., Lee, B.L., Söderhäll K., Söderhäll, I., 2011. Peptidoglycan activation of the proPO-system without a peptidoglycan receptor protein (PGRP)? Developmental and Comparative Immunology 35, 51-61.

Lofgren, S.E., Miletti, L.C., Steindel, M., Bachère, E., Barracco, M.A., 2008. Trypanocidal and leishmanicidal activities of different antimicrobial peptides (AMPS) isolated from aquatic animals. Experimental Parasitology 118, 197-202.

Lofgren, S.E., Smania, A., Smania, E.D.A., Bachère, E., Barracco, M.A., 2009. Comparative activity and stability under salinity conditions of different antimicrobial peptides isolated from aquatic animals. Aquaculture Research 40, 1805-1812.

Lorenzon, S., De Guarrini, S., Smith, V.J., Ferrero, E.A., 1999. Effects of LPS on circulating haemocytes in crustaceans in vivo. Fish and Shellfish Immunology 9, 31-50.

Luo, T., Yang, H.J., Li, F., Zhang, X.B., Xu, X., 2006. Purification, characterization and cDNA cloning of a novel lipopolysaccharide-binding lectin from the shrimp Penaeus monodon. Developmental and Comparative Immunology 30, 607-617. 
Luo, T., Zhang, X.B., Shao, Z.Z., Xu, X., 2003. PmAV, a novel gene involved in virus resistance of shrimp Penaeus monodon. FEBS Letters 551, 53-57.

Ma, T.H.T, Tiu, S.H.K., He, J.-G., Chan, S.-M., 2007. Molecular cloning of a C-type lectin (LvLT) from the shrimp Litopenaeus vannamei: Early gene down-regulation after WSSV infection. Fish and Shellfish Immunology 23, 430-437.

Mekata, T., Kono, T., Yoshida, T., Sakai, M., Itami, T., 2008. Identification of cDNA encoding Toll receptor, MjToll gene from kuruma shrimp, Marsupenaeus japonicus. Fish and Shellfish Immunology 24, 122-133.

Molthathong, K., Senapin, S., Klinbunga, S., Puanglarp, N., Rojtinnakorn, J., Flegel, T.W., 2008. Down-regulation of defender against apoptotic death (DAD1) after yellow head virus (YHV) challenge in black tiger shrimp Penaeus monodon. Fish and Shellfish Immunology 24, 173-179

Passarelli, L., Hall, A., 2011. A gut feeling: how baculoviruses establish systemic infection. Presented at $44^{\text {th }}$ Annual Meeting of the Society for Invertebrate Pathology, Halifax Canada, 7 $11^{\text {th }}$ August 2011.

Prapavorarat, A., Pongsomboon, S., Tassanakajon, A., 2010. Identification of genes expressed in response to yellow head virus infection in the black tiger shrimp, Penaeus monodon, by suppression subtractive hybridization. Developmental and Comparative Immunology 34, 611-617.

Powell, E.N., Klinck, J.M., Hoffman, E.E., 1996. Modelling diseased oyster populations, 2 triggering mechanisms for Perkinsus marinus epizootics. Journal of Shellfish Research 15, 141165.

Relf, J.M., Chisholm, J.R.S., Kemp, G.D., Smith, V.J., 1999. Purification and characterization of a cysteine-rich 11.5-kDa antibacterial protein from the granular haemocytes of the shore crab, Carcinus maenas. European Journal of Biochemistry 264, 350-357.

Riddell, C.E., Sumner, S., Adams, S., Mall, E.B., 2011. Pathways to immunity: temporal dynamics of the bumblebee (Bombus terrestris) immune response against a trypanosomal gut parasite. Insect Molecular Biology 20, 529-540.

Rodríguez-Ramos, T., Carpio, Y., Bolívar, J., Espinosa, G., Hernández-López, J., Gollas-Galván, T., Ramos, L., Pendón, C., Estrada, M.P., 2010. An inducible nitric oxide synthase (NOS) is expressed in haemocytes of the spiny lobster Panulirus argus: Cloning, characterization and expression analysis. Fish and Shellfish Immunology 29, 469-479.

Roulston, C., Smith, V.J., 2011. Isolation and in vitro characterisation of prohaemocytes from the spider crab, Hyas araneus (L.). Developmental and Comparative Immunology 35, 537-544. 
Sakai, M., Fall, J., Kono, T., Tanekhy, M., Itami, T., 2010. Expression of innate immune-related genes of Kuruma shrimp, Marsupenaeus japonicus, after challenge with Vibrio nigripulchritudo. African Journal of Microbiology Research 4, 2426-2433.

Schmucker, D., Clemens, J.C., Shu, H., Worby, C.A., Xiao, J., Muda, M., Dixon, J.E., Zipursky, S.L., 2000. Drosophila Dscam is an axon guidance receptor exhibiting extraordinary molecular diversity. Cell 101, 671-684.

Sequeira, T., Tavares, D., Arala-Chaves, M., 1996. Evidence for circulating hemocyte proliferation in the shrimp, Penaeus japonicus. Developmental and Comparative Immunology 20, 97-104.

Shi, X.-Z., Zhang, R.-R., Jia, Y.-P., Zhao, X.-F., Yu, X.-Q., Wang, J.-X., 2009. Identification and molecular characterization of a Spätzle-like protein from Chinese shrimp (Fenneropenaeus chinensis). Fish and Shellfish Immunology 27, 610-617.

Shockey, J.E., O’Leary, N.A., de la Vega, E., Browdy, C.L., Baatz, J.E., Gross, P.S., 2009. The role of crustins in Litopenaeus vannamei in response to infection with shrimp pathogens: An in vivo approach. Developmental and Comparative Immunology 33, 668-673.

Simonet, G., Claeys, I., Franssens, V., De Loof, A., Vanden Broeck, J., 2003. Genomics, evolution and biological functions of the pacifastin peptide family: a conserved serine protease inhibitor family in arthropods Peptides 24, 1633-1644.

Smith V.J., Brown, J.H., Hauton, C., 2003. Immunostimulation in crustaceans: does it protect against infection? Fish and Shellfish Immunology 15, 71-90.

Smith, V.J., Fernandes, J.M.O., Kemp, G., Hauton C., 2008. Crustins - enigmatic WAP domain containing antibacterial proteins from crustaceans. Developmental and Comparative Immunology $32,758-772$.

Smith, V.J., Ratcliffe, N.A., 1980. Cellular defence reactions of the shore crab Carcinus maenas: in vivo haemocytic and histopathological responses to injected bacteria. Journal of Invertebrate Pathology 35, 65-74.

Söderhäll, I., Bangyeekhun, E., Mayo, S., Söderhäll, K., 2003. Hemocyte production and maturation in an invertebrate animal: proliferation and gene expression in hematopoietic stem cells of Pacifastacus leniusculus. Developmental and Comparative Immunology 27, 661-672.

Söderhäll, I., Donpudsa, S., Rimphanitchayakit, V., Tassanakajon, A., Söderhäll, K., 2010. Characterization of two crustin antimicrobial peptides from the freshwater crayfish Pacifastacus leniusculus. Journal of Invertebrate Pathology 104, 234-238. 
Söderhäll, K., Smith, V.J., 1983. Separation of the haemocyte population of Carcinus maenas and other marine decapods and phenoloxidase distribution. Developmental and Comparative Immunology 7, 229-239.

Soma, G.I., Kadowaki, T., Inagawa, H., Kohchi, C., Nishizawa, T., Takahashi, Y., 2011. Antilipopolysaccharide Factor Evokes Indirect Killing of Virulent Bacteria in Kuruma Prawn. In Vivo $25,741-744$.

Soonthornchai, W., Rungrassamee, W., Karoonuthaisiri, N., Jarayabhand, P., Klinbunga, S., Söderhäll, K., Jiravanichpaisal, P., 2011. Expression of immune-related genes in the digestive organ of shrimp, Penaeus monodon, after an oral infection by Vibrio harveyi. Developmental and Comparative Immunology 34, 19-28.

Sperstad, S.V., Smith, V.J., Stensvag, K. 2010. Expression of antimicrobial peptides from Hyas araneus haemocytes following bacterial challenge in vitro. Developmental and Comparative Immunology 34, 618-624.

Sriphaijit, T., Flegel, T.W., Senapin, S., 2007. Characterization of a shrimp serine protease homolog, a binding protein of yellow head virus. Developmental and Comparative Immunology $31,1145-1158$.

Sritunyalucksana, K., Söderhäll, K., 2000. The proPO and clotting system in crustaceans. Aquaculture 191, 53-69.

Sritunyalucksana, K., Wannapapho, W., Lo, C.F., Flegel, T.W., 2006. PmRab7 is a VP28-binding protein involved in white spot syndrome virus infection in shrimp. Journal of Virology 80, 1073410742.

Stein, D., Roth, S., Vogelsang, E., Nusslein-Volhard, C., 1991. The polarity of the dorsoventral axis in the Drosophila embryo is defined by an extracellular signal. Cell 65, 725-735.

Stentiford, G.D., Neil, D.M., Peeler, E., Shields, J.D., Small, H.J., Flegel, T.W., Vlak, J., Jones, B., Morado, F., Moss, S., Lotz, J., Bartholomay, L., Reantaso, M., Behringer, D.C., Hauton, C., Lightner, D.V. (2012). Disease will limit future food supply from the global crustacean fishery and aquaculture sectors . J. Invert. Pathol. (in press, this volume).

Subasinghe, R., Soto, D., Jia, J.S., 2009. Global aquaculture and its role in sustainable development. Reviews in Aquaculture 1, 2-9.

Sung, H.H., Kuo, P.A., Kao, W.Y., 2000. Effect of lipopolysaccharide on in vitro phagocytosis by hemocytes from giant freshwater prawn (Macrobrachium rosenbergii) Fish Pathology 35, 109116. 
Tang, K.F.J., Durand, S.V., White, B.L., Redman, R.M., Mohney, L.L., Lightner, D.V., 2003. Induced resistance to white spot syndrome virus infection in Penaeus stylirostris through preinfection with infectious hypodermal and hematopoietic necrosis virus - a preliminary study. Aquaculture 216, 19-29.

Tang, K.F.J., Lightner, D.V., 2006. Infectious hypodermal and hematopoietic necrosis virus (IHHNV)-related sequences in the genome of the black tiger prawn Penaeus monodon from Africa and Australia. Virus Research 118, 185-191.

Tassanakajon, A., Amparyup, P., Somboonwiwat, K., Supungul, P., 2010. Cationic antimicrobial peptides in penaeid Shrimp. Marine Biotechnology 12, 487-505.

Towle, D.W., Beale, K.M., Jayasundara, N., Smith, C.M., Shields, J.D., Small, H.J., Greenwood, S.J., 2008. Anti-lipopolysaccharide factors in the American lobster Homarus americanus:

Molecular characterization and transcriptional response to Vibrio fluvialis challenge. Comparative Biochemistry and Physiology D-Genomics \& Proteomics 3, 263-269.

Tsai, M-F., Kou, G-S., Liu, H-C., Liu, K-F., Chang, C-F., Peng, S-E., Hsu, H-C., Wang, C-H., Lo C-F., 1999. Long-term presence of white spot syndrome virus (WSSV) in a cultivated shrimp population without disease outbreaks. Diseases of Aquatic Organisms 38, 107-114.

Tsing, A., Arcier, J.-M., Brehélin, M., 1989. Hemocytes of penaeid and palaemonid shrimps: Morphology, cytochemistry and hemograms. Journal of Invertebrate Pathology 53, 64-77. Vargas-Albores, F., Yepiz-Plascencia, G., 2000. Beta glucan binding protein and its role in shrimp immune response. Aquaculture 191, 13-21.

Vargas-Albores F, Yepiz-Plascencia G, Jimenez-Vega F, Avila-Villa A., 2004. Structural and functional differences of Litopenaeus vannamei crustins. Comparative Biochemistry and Physiology B-Biochemistry and Molecular Biology 138, 415-422.

Verschuere, L., Rombaut, G., Sorgeloos, P., Verstraete, W., 2000. Probiotic bacteria as biological control agents in aquaculture. Microbiology and Molecular Biology Reviews 64, 655-671.

Vici, V., Bright Singh, I.S., Bhat, S.G., 2000. Application of bacterins and yeast Acremonium dyosporii to protect the larvae of Macrobrachium rosenbergii from vibriosis. Fish and Shellfish Immunology 10, 559-563.

Wang, R., Lee, S.Y., Cerenius, L., Söderhäll, K., 2001. Properties of the prophenoloxidase activating enzyme of the freshwater crayfish, Pacifastacus leniusculus. European Journal of Biochemistry 268, 895-902. 
Wang, L.L., Mu, C.K., Zheng, P.L., Zhao, J.M., Qiu, L.M., Zhang, H., Gai, Y.C., Song, L.S., 2011a. A novel type III crustin (CrusEs2) identified from Chinese mitten crab Eriocheir sinensis. Fish \& Shellfish Immunology 31, 142-147.

Wang, J.X., Sun, C., Xu, W.T., Zhang, H.W., Dong, L.P., Zhang, T., Zhao, X.F., 2011b. An antilipopolysaccharide factor from red swamp crayfish, Procambarus clarkii, exhibited antimicrobial activities in vitro and in vivo. Fish and Shellfish Immunology 30, 295-303.

Watson, F.L., Püettmann-Holgado, R., Thomas, F., Lamar, D.L., Hughes, M., Kondo, M., Rebel, V.I., Schmucker, D., 2005. Extensive diversity of Ig-superfamily proteins in the immune system of insects. Science 309, 1874-1878.

Watthanasurorot, A., Jiravanichpaisal, P., Liu, H., Söderhäll, I., Söderhäll, K., 2011. Bacteriainduced Dscam isoforms of the crustacean, Pacifastacus leniusculus. PLOS Pathogens 7 , e1002062.

West, A.P., Koblansky, A.A., Ghosh, S., 2006. Recognition and signalling by Toll-like receptors. Annual Review of Cell and Developmental Biology 22, 409-437.

Witteveldt, J., Cifuentes, C.C., Vlak, J.M., van Hulten, M.C., 2004. Protection of Penaeus monodon against White Spot Syndrome Virus by oral vaccination. Journal of Virology 78, 2057-2061.

Witteveldt, J., Vlak, J.M., van Hulten, M.C., 2006. Increased tolerance of Litopenaeus vannamei to White Spot Syndrome Virus (WSSV) infection after oral application of the viral envelope protein VP28. Disease of Aquatic Organisms 70, 167-170.

Woramongkolchai, N., Supungul, P., Tassanakajon, A., 2011. The possible role of penaeidin5 from the black tiger shrimp, Penaeus monodon, in protection against viral infection. Developmental and Comparative Immunology 35, 530-536.

Xian, J.-A., Wang, A.-Li., Tian, J.-X. Huang, J.-W., Ye, C.-X., Wang, W.-N., Sun, R.-Y., 2009. Morphologic, physiological and immunological changes of haemocytes from Litopenaeus vannamei treated by lipopolysaccharide. Aquaculture 298, 139-145.

Yang, H.J., Luo, T., Li, F., Li, S.J., Xu, X., 2007. Purification and characterisation of a calciumindependent lectin (PjLec) from the haemolymph of the shrimp Penaeus japonicus. Fish and Shellfish Immunology 22, 88-97.

Yang, H.L., Wang, K.C.H.C., Tseng, C.W., Lin, H.Y., Chen, I.T., Chen, Y.H., Chen, Y.M., Chen, T.Y., 2010. RNAi knock-down of the Litopenaeus vannamei Toll gene (LvToll) significantly increases mortality and reduces bacterial clearance after challenge with Vibrio harveyi. Developmental and Comparative Immunology 34, 49-58. 
Yang, L.-S., Yin, Z.-X., Liao, J.-X., Huang, X.-D., Guo, C.-J., Weng, S.-P., Chan, S.-M., Yu, X.-Q., He, J.-G., 2007. A Toll receptor in shrimp. Molecular Immunology 44, 1999-2008.

Yang, C., Zhang, J., Li, F., Ma, H., Zhang, Q., Priya, T.A., Zhang, X., Xiang, J., 2008. A Toll receptor from Chinese shrimp Fenneropenaeus chinensis is responsive to Vibrio anguillarum infection. Fish and Shellfish Immunology 24, 564-574.

Yeh M.S., Huang C.J., Leu J.H., Lee Y.C., Tsai I.H., 1999. Molecular cloning and characterization of a hemolymph clottable protein from tiger shrimp Penaeus monodon. European Journal of Biochemistry 266, 624-633.

Yepiz-Plascencia, G., Vargas-Albores, F., Jimenez-Vega, F., Ruiz-Verdugo, L.M., Romo-Figueroa, G., 1998. Shrimp plasma HDL and beta-glucan binding protein (BGBP): comparison of biochemical characteristics. Comparative Biochemistry and Physiology B - Biochemistry and Molecular Biology 121, 309-314. 


\section{LEGENDS}

Figure 1. Summary of the domain structure of Down-Syndrome Cell Adhesion Molecule (DSCAM) proteins identified in crustaceans, showing the exon splice-variable Ig 2, Ig3 and Ig7 domains that compare with the invariant domain structure of vertebrate DSCAM. Extreme splice variation within invertebrate phyla has recently been presented as a mechanism to support specificity within the innate immune response. Note that membrane bound and soluble DSCAM variants have been reported in the invertebrates, see text for further discussion. Figure adapted from Brites et al. (2008) incorporating Chou et al. (2009 and 2011) and Watthanasurorot et al. (2011).

Table 1. Overview of some examples of the range of activity identified for each of the three main groups of antimicrobial peptide identified in decapod crustaceans. In this table AMP activities have been summarised by main family and are not resolved at the level of isoforms. A tick $(\checkmark)$ indicates publications in which 'activity' has been reported, a cross ( $(x)$ indicates publications where specifically 'no activity' has been identified against a particular class of pathogen. Empty boxes indicate no data (positive or negative) available in the literature. Citations in italics indicate studies of transcriptional regulation only. 
FIGURE 1

Penaeus vannamei and $\boldsymbol{P}$ monodon form 1

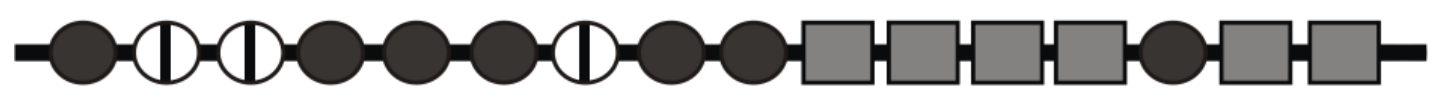

Pacifastacus leniusculus, Daphnia spp.

and $\boldsymbol{P}$ monodon form 2

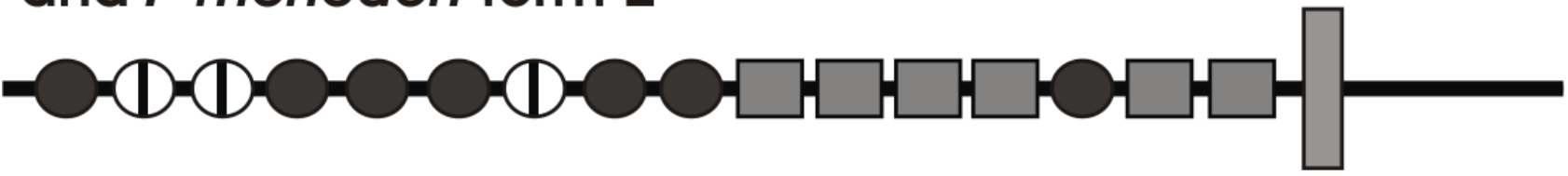

\section{Vertebrate form}

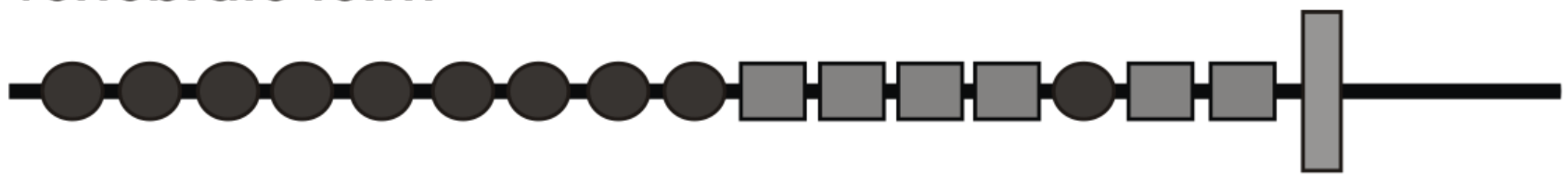

Conserved lg-like domains

(D) Transcriptionally variant Ig-like domains 
TABLE 1.

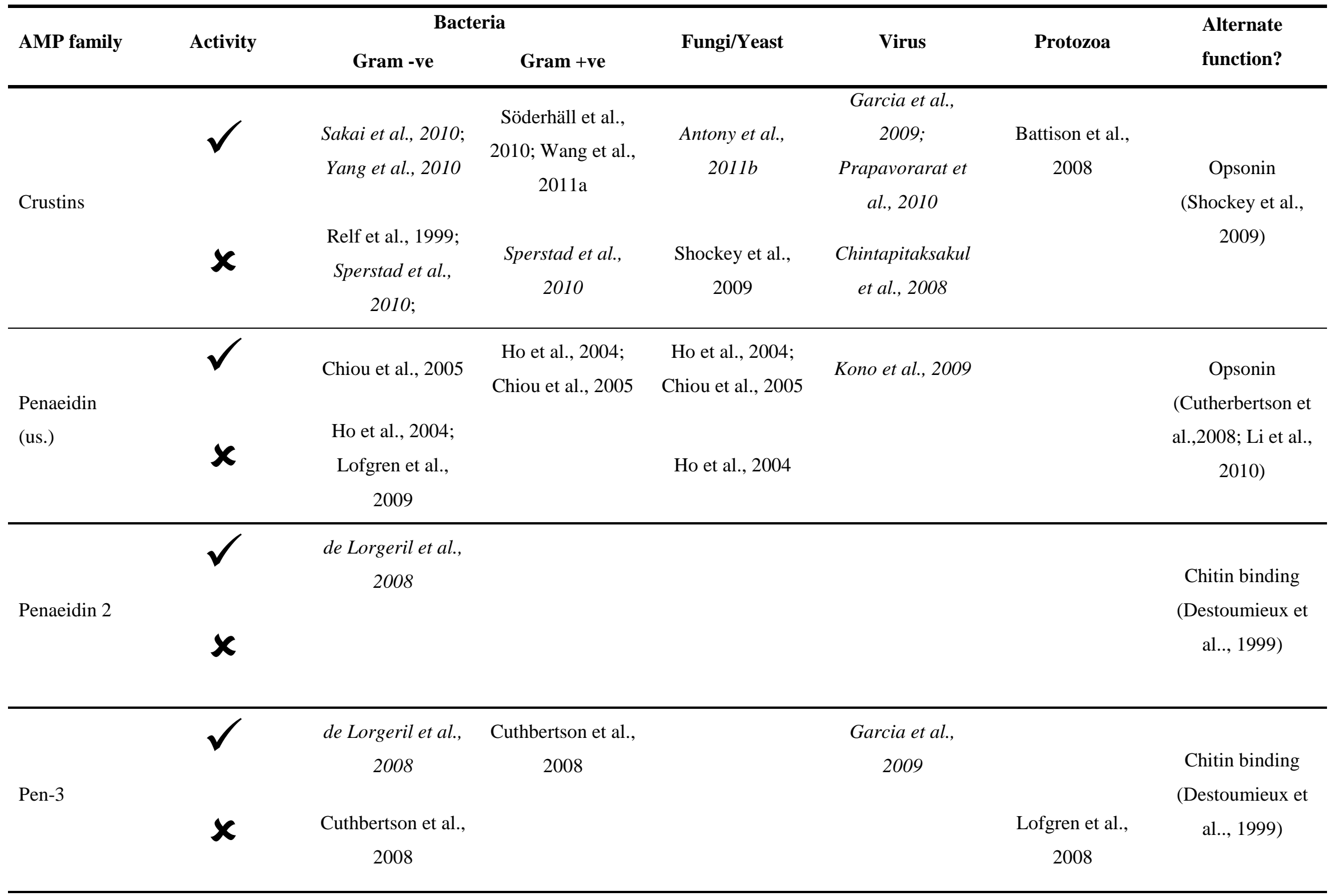




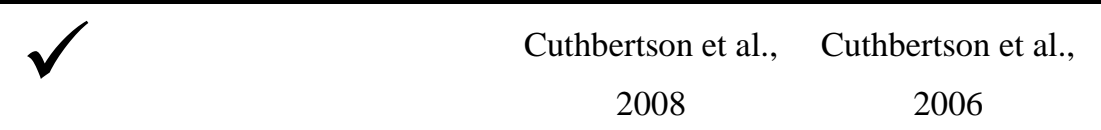

Pen 4

X Cuthbertson et al.,

2008

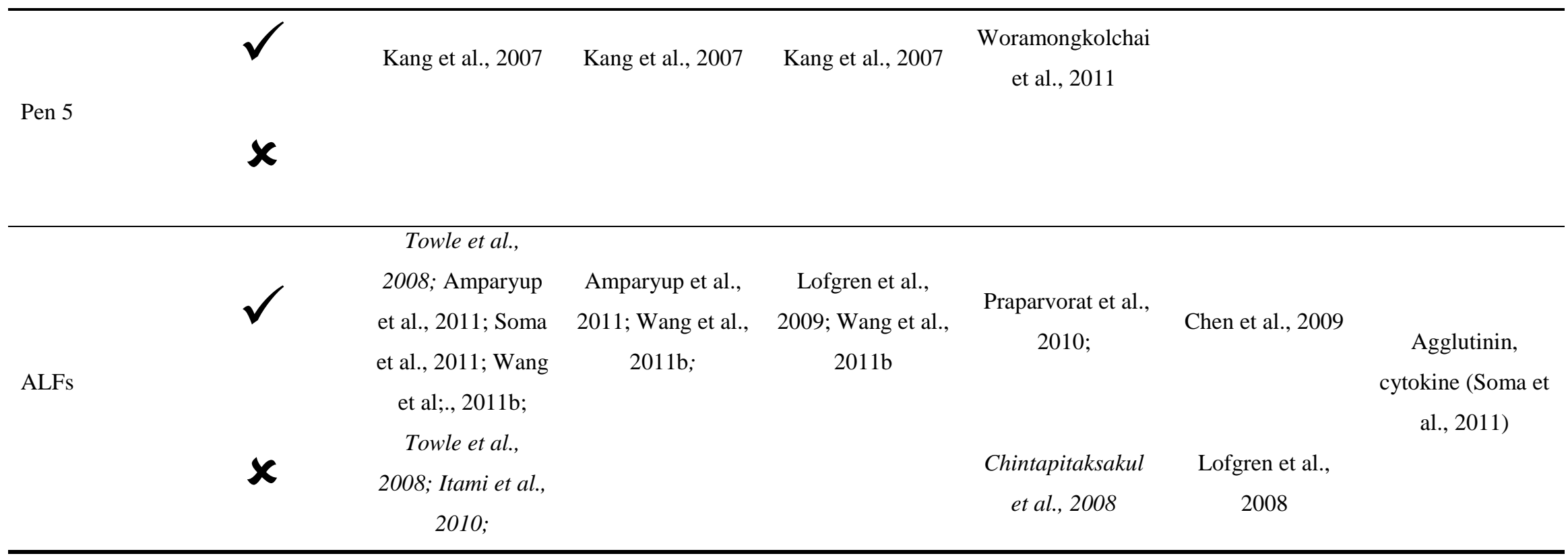

(Pen = penaeidin class; u.s. $=$ unspecified $;$ ALFs= anti-lipopolysaccharide factors $)$ 